\title{
Nanoplankton fraction in the phytoplankton structure in the southern Gulf of Mexico (April 2000)
}

\section{Fracción de nanoplancton en la estructura del fitoplancton en el sur del Golfo de México (abril de 2000)}

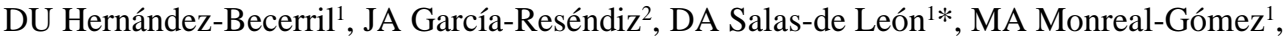 \\ M Signoret-Poillon ${ }^{3}$, J Aldeco-Ramírez ${ }^{2,3}$ \\ ${ }^{1}$ Instituto de Ciencias del Mar y Limnología, Universidad Nacional Autónoma de México (UNAM), Apartado postal 70-305, \\ México DF 04510, Mexico.*E-mail: salas@mar.icmyl.unam.mx \\ 2 Posgrado en Ciencias del Mar y Limnología, Universidad Nacional Autónoma de México (UNAM), Apartado postal 70-305, \\ México DF 04510, Mexico. \\ ${ }^{3}$ Departamento El Hombre y su Ambiente, Universidad Autónoma Metropolitana-Xochimilco, México, DF 04960, México.
}

\begin{abstract}
Phytoplankton, especially the nanoplankton fraction, and its possible relationships with the hydrographic conditions in the southern Gulf of Mexico were studied during an oceanographic cruise in April 2000. Hydrographic data and phytoplankton were analyzed. Phytoplankton species composition showed heterogeneity among stations. A total of 180 species were found: 114 diatoms, 32 dinoflagellates, 32 coccolithophores, and 2 silicoflagellates. Diversity indices were variable $\left(0.96-5.12\right.$ bits ind $\left.{ }^{-1}\right)$. Phytoplankton was numerically dominated by coccolithophores or nanoplanktonic diatoms. Cell abundance was low to moderately high, ranging from $5.3 \times 10^{3}$ to $1.4 \times 10^{5}$ cells $\mathrm{L}^{-1}$. The most abundant, dominant species were nanoplanktonic forms: two coccolithophores, Emiliania huxleyi and Gephyrocapsa oceanica; the pennate diatoms Nitzschia bicapitata, N. bifurcata and N. leehyi; and centric diatoms of the genus Thalassiosira. The high subsurface abundance of coccolithophores at two stations was related to a thermal front in the Grijalva-Usumacinta river system.
\end{abstract}

Key words: nanoplankton, chlorophyll $a$, coccolithophores, diatoms, Gulf of Mexico.

\section{Resumen}

Se estudió la fracción del fitoplancton que corresponde al nanoplancton y sus posibles relaciones con las condiciones hidrográficas en el sur del Golfo del México durante un crucero oceanográfico realizado en abril de 2000. Se analizaron datos hidrográficos y muestras de fitoplancton. La composición de las especies del fitoplancton mostró heterogeneidad entre las estaciones. Se encontraron 180 especies: 114 diatomeas, 32 dinoflagelados, 32 cocolitofóridos y dos silicoflagelados. Los índices de diversidad fueron variables (0.96-5.12 bits ind ${ }^{-1}$ ). Los cocolitofóridos y las diatomeas nanoplanctónicas fueron los grupos dominantes. La abundancia de células fue de baja a ligeramente alta, yendo de $5.3 \times 10^{3}$ a $1.4 \times 10^{5}$ cél $\mathrm{L}^{-1}$. Las especies más abundantes, de las dominantes fueron las formas nanoplanctónicas: dos cocolitoforidos, Emiliania huxleyi y Gephyrocapsa oceanica, las diatomeas pennadas, Nitzschia bicapitata, $N$. bifurcata y $N$. leehyi, y las especies de diatomeas céntricas Thalassiosira. La alta abundancia subsuperficial de cocolitoforidos en dos estaciones estuvo relacionada con el frente térmico de la pluma del sistema de ríos Grijalva-Usumacinta.

Palabras clave: nanoplancton, clorofila a, cocolitofóridos, diatomeas, Golfo de México.

\section{Introduction}

The southern Gulf of Mexico is highly productive, and large commercial fisheries and the oil industry make this region economically important. In this area the continental shelf is extensive and includes part of the Yucatan peninsula shelf. The coastal waters, including coastal lagoons, wetlands and barrier islands, provide important wildlife habitats, with high biological diversity.

The Bay of Campeche (fig. 1) is characterized by a cyclonic eddy that is formed in the bay and drifts westward, facilitating transport and distribution of planktonic organisms. The eddy provides larval transport from oceanic to coastal areas and vice versa. The seasonal distribution of fish larvae is

\section{Introducción}

El sur del Golfo de México es altamente productivo, con gran cantidad de pesquerías comerciales y una importante industria petrolera, lo que hace de ésta una región económicamente importante. En esta área la plataforma continental es extensa e incluye parte de la plataforma de la Península de Yucatán. La zona costera contiene lagunas, humedales e islas que son importantes hábitats para la vida marina, con una gran diversidad biológica.

La Bahía de Campeche (fig. 1) se caracteriza por un giro ciclónico que se forma y deriva hacia el oeste, facilitando el transporte y distribución de organismos planctónicos. Los giros promueven el transporte de larvas de las áreas oceánicas hacia 
significantly influenced by the position of the eddy. Biomass distribution and the density of fish larvae are governed by coastal fronts (Salas-de León et al. 1998, Sánchez-Iturbe et al. 2006) formed by the affluents of the main rivers in the southern gulf: the Grijalva-Usumacinta river system and the Coatzacoalcos River (fig. 1). Lowest runoff from these rivers is observed in April (Czitrom et al. 1986). The Grijalva-Usumacinta river system is responsible for most fresh-water flow into the southern Gulf of Mexico, representing 30\% of Mexico's freshwater resource (Ortiz-Zamora et al. 2002), and its influence generates important coastal fronts (Czitrom et al. 1986, Monreal-Gómez et al. 1992).

A noticeable subsurface thermal gradient has been observed on the shelf break of Campeche Bank, which corresponds to an upward tilting (doming) of low-oxygen ( $<90 \%$ saturation content) mid-water to near the base of the mixed layer, and an anticyclone-cyclone pair occurs over Campeche Canyon (Salas-de León et al. 2004). The presence of the doming and anticyclonic-cyclonic pair exerts a noticeable effect on chlorophyll $a$ content and suspended particulate matter at their boundaries (Salas-de León et al. 2004), and on phytoplankton abundance (López-Calderón et al. 2006).

In the southern Gulf of Mexico many studies have been conducted on various ecological aspects of phytoplankton, including primary productivity (Cruz 1971; Hulburt and Corwin 1972; Kabanova and López-Baluja 1973; Santoyo and Signoret 1973, 1975; Zernova 1974; Furnas and Smayda 1987; Licea and Santoyo 1991; Licea and Luna 1999; Okolodkov 2003; Signoret et al. 1998), and the floristics and taxonomy of certain genera or groups of phytoplankton (Moreno-Ruiz et al. 1993, Licea 1994, Moreno and Licea 1994, HernándezBecerril 1998, Hernández-Becerril and Flores 1998, Licea et al. 2004). Licea and Luna (1999) recorded the highest biomass values during the rainy season (July-August), with maximum abundances of $6.3 \times 10^{6}$ cells $\mathrm{L}^{-1}$, and the lowest during winter (November-December), but no details of species composition were given.

Most studies have concentrated on diatoms and dinoflagellates since they have been traditionally considered the main contributors to biomass and productivity within the gulf (Balech 1967, Saunders and Glenn 1969, Norris and Berner 1970, Steidinger and Williams 1970, Licea et al. 2004). Hulburt and Corwin (1972) found planktonic flora dominated by the coccolithophores Emiliania (Coccolithus) huxleyi and Gephyrocapsa oceanica, and diatoms Hemiaulus indicus and Pseudo-nitzschia (Nitzschia) delicatissima in the southern Gulf of Mexico. Gaarder and Hasle (1971) described the coccolithophores from the entire gulf. Few papers, however, include other groups, such as phytoflagellates, which have been found to be significant in other regions of the world.

The purpose of this study was to describe the phytoplankton community structure, especially the nanoplankton fraction, and its relationship with the hydrographic conditions in three different zones of the southern Gulf of Mexico, considering only the preservable phytoplankton fraction, including las costeras y viceversa. La distribución estacional de larvas de peces es influenciada por la posición del giro. La distribución de biomasa y la densidad de larvas de peces también son influenciadas por los frentes costeros (Salas-de León et al. 1998, Sánchez-Iturbe et al. 2006) que se forman por las descargas de los principales ríos en el sur del golfo: el sistema Grijalva-Usumacinta y el Río Coatzacoalcos (fig. 1). En abril las descargas de estos ríos son bajas (Czitrom et al. 1986). El sistema de ríos Grijalva-Usumacinta es el responsable de las mayores descargas en el sur del Golfo de México, representando 30\% del agua dulce descargada (Ortiz-Zamora et al. 2002), y su influencia genera importantes frentes costeros (Czitrom et al. 1986, Monreal-Gómez et al. 1992).

Se ha observado un importante gradiente térmico subsuperficial sobre el borde de la plataforma continental del Banco de Campeche el cual corresponde a un domo de bajo contenido de oxígeno (menor a 90\% de saturación) cercano a la base de la capa de mezcla y, un par anticiclón-ciclón sobre el Cañón de Campeche (Salas-de León et al. 2004). La presencia del domo y de la frontera del par anticiclón-ciclón ejerce un efecto importante sobre el contenido de clorofila $a$ y de materia particulada suspendida (Salas-de León et al. 2004), y en la abundancia del fitoplancton (López-Calderón et al. 2006).

En el sur del Golfo de México se han realizado varias investigaciones sobre aspectos ecológicos del fitoplancton, incluyendo datos sobre productividad primaria (Cruz 1971; Hulburt y Corwin 1972; Kabanova y López-Baluja 1973; Santoyo y Signoret 1973, 1975; Zernova 1974; Furnas y Smayda 1987; Licea y Santoyo 1991; Licea y Luna 1999; Okolodkov 2003; Signoret et al. 1998), sobre florística y taxonomía de ciertos géneros o grupos del fitoplancton (Moreno-Ruiz et al. 1993, Licea 1994, Moreno y Licea 1994, Hernández-Becerril 1998, Hernández-Becerril y Flores 1998, Licea et al. 2004). Licea y Luna (1999) reportaron los valores más altos de biomasa durante la época de lluvias (julio a

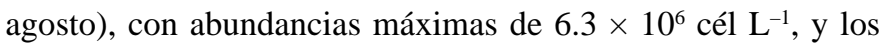
valores más bajos durante el invierno (noviembre a diciembre); sin embargo, no dan detalles de la composición de las especies.

La mayoría de los estudios se han enfocado en las diatomeas y los dinoflagelados, ya que éstos han sido tradicionalmente considerados como los grupos que más contribuyen a la biomasa y productividad en el golfo (Balech 1967, Saunders y Glenn 1969, Norris y Berner 1970, Steidinger y Williams 1970, Licea et al. 2004). Hulburt y Corwin (1972) encontraron que la flora planctónica en el sur del Golfo de México es dominada por los cocolitofóridos Emiliania (Coccolithus) huxleyi y Gephyrocapsa oceanica y las diatomeas Hemiaulus indicus, Pseudo-nitzschia (Nitzschia) delicatissima. Gaarder y Hasle (1971) describieron los cocolitofóridos a lo largo del golfo, pero pocas publicaciones han incluido otros grupos como los fitoflagelados, los cuales han sido considerados importantes en otras regiones del mundo.

El propósito de este estudio fue describir la estructura de la comunidad fitoplanctónica, especialmente la fracción del nanoplancton, su relación con la condiciones hidrográficas del sur 


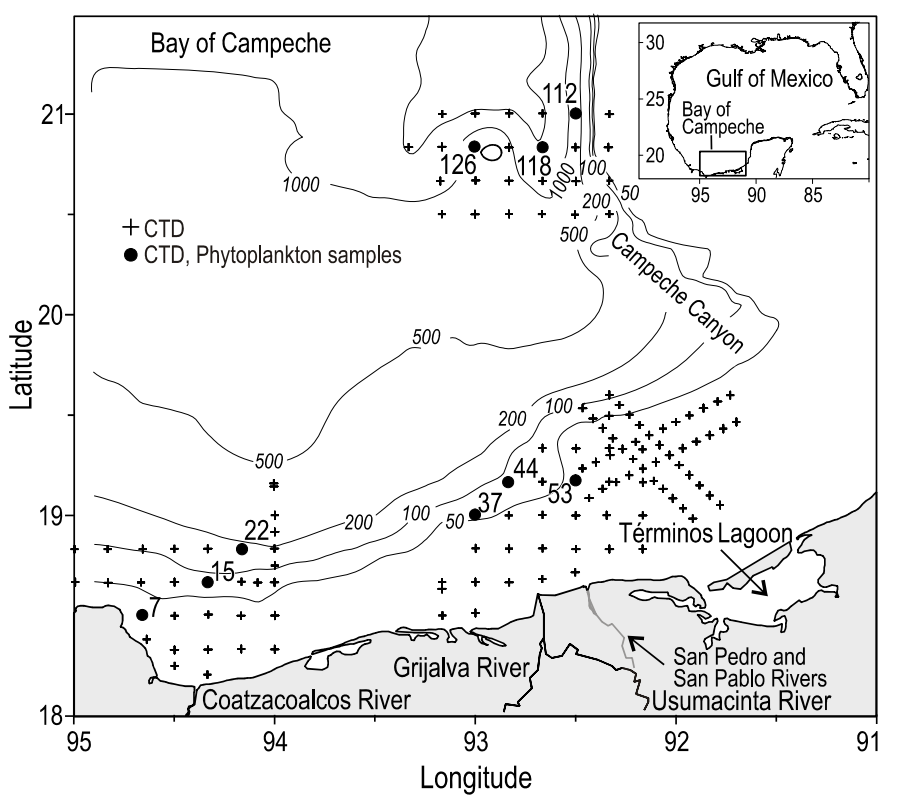

Figure 1. Location of the study area in the southern Gulf of Mexico and network of stations sampled. Depth in meters.

Figura 1. Localización de la región de estudio en el sur del Golfo de México y red de estaciones de muestreo. Profundidades en metros.

diatoms, mainly thecate dinoflagellates, silicoflagellates and coccolithophores.

\section{Material and methods}

Data and samples were obtained during an oceanographic cruise, PROMEBIO III (Ocean Processes and Biological Production Mechanisms in the Southern Gulf of Mexico), from 6 to 19 April 2000, conducted on board UNAM's R/V Justo Sierra in the southern Gulf of Mexico (fig. 1). A CTD was used to record conductivity, temperature, and pressure. Salinity and density $\left(\sigma_{t}\right)$ were calculated following the UNESCO algorithms for computation of fundamental properties of seawater (Fofonoff and Millard 1983). Salinity samples were assessed with an induction salinometer.

Phytoplankton samples were taken with bottles at nine fixed stations in three different zones (fig. 1): three located in the coastal zone near the mouth of the Coatzacoalcos River (stations 7, 15, 22), three close to the Grijalva-Usumacinta river system (stations $37,44,53$ ), and three in the oceanic zone over Campeche Canyon (stations 112, 118, 126). Samples were collected at three depths in an attempt to sample phytoplankton at or around the deep chlorophyll maximum (DCM). Phytoplankton samples (usually $4 \mathrm{~L}$ ) were filtered through 47-mmdiameter Millipore membrane filters $(0.45 \mu \mathrm{m})$ using a vacuum pump (less than $100 \mathrm{~mm} \mathrm{Hg}$ ). Filters were immediately rinsed with distilled water $(10-20 \mathrm{~mL}, \mathrm{pH} 7)$ to remove sea salt, airdried at room temperature, and stored in plastic Petri dishes (Winter et al. 1999, Bollmann et al. 2002).

Small pieces (approximately $1 \mathrm{~cm}^{2}$ ) of the filters containing phytoplankton were cut and mounted onto slides, and del Golfo de México en tres zonas diferentes, considerando solamente la fracción preservable del fitoplancton, incluyendo las diatomeas, principalmente los dinoflagelados tecados, los silicoflagelados y los cocolitofóridos.

\section{Material y métodos}

Los datos hidrográficos y las muestras de fitoplancton fueron obtenidos durante el crucero oceanográfico PROMEBIO III (Procesos Oceánicos y Mecanismos de Producción Biológica en el sur del Golfo de México), a bordo del B/O Justo Sierra de la UNAM, en el sur del Golfo de México, del 6 al 19 de abril de 2000 (fig. 1). Se registró la conductividad, la temperatura y la presión con un CTD, y se calcularon la salinidad y la densidad $\left(\sigma_{t}\right)$ usando los algoritmos de la UNESCO (Fofonoff y Millard 1983). Las muestras de salinidad fueron corroboradas con un salinómetro de inducción.

Las muestras de fitoplancton fueron tomadas con botellas en nueve estaciones de tres regiones: tres estaciones en la zona costera próxima a la desembocadura del Río Coatzacoalcos (estaciones 7, 15 y 22), tres cerca de los ríos GrijalvaUsumacinta (estaciones 37, 44 y 53) y tres en la zona oceánica sobre el Cañón de Campeche (estaciones 112, 118 y 126) (fig. 1 ), en tres profundidades, tratando de tener muestras de fitoplancton cerca del máximo profundo de clorofila (DCM). Las muestras de fitoplancton (aproximadamente $4 \mathrm{~L}$ ) fueron filtradas a través de membranas de filtros Millipore $(0.45 \mu \mathrm{m})$, con un diámetro de $47 \mathrm{~mm}$, usando una bomba de vacío $(<100$ $\mathrm{mm} \mathrm{Hg}$ ). Los filtros fueron enjuagados inmediatamente con agua destilada (10-20 mL, $\mathrm{pH}$ 7) para eliminar la sal del agua de mar, secados a temperatura ambiente y guardados en cajas de Petri (Winter et al. 1999, Bollmann et al. 2002).

Se cortaron partes pequeñas de los filtros (aproximadamente $1 \mathrm{~cm}^{2}$ ), se montaron en portaobjetos y se añadió aceite de inmersión para aclarar el filtro; después fueron cubiertos y se observaron en microscopio de luz (LM), usando campo brillante y amplificación total de $\times 600$ o $\times 1250$, para contar e identificar las especies, respectivamente (Bollmann et al. 2002). La identificación y el conteo preliminar de especies se hicieron usando LM y la estimación del número de células por litro, se realizó mediante datos como el número de organismos contados, las áreas contadas y filtradas y el volumen filtrado, con un límite de detección entre 300 y 3000 cél $^{-1}$ (Bollmann et al. 2002). Para confirmar la identificación de las especies se realizaron observaciones con microscopio electrónico de barrido (SEM) usando pequeñas piezas de filtro tratadas convencionalmente para SEM (Bollmann et al. 2002). Se encontraron muy pocas células colapsadas (por efecto del cambio de $\mathrm{pH}$ o la bomba de vacío). Todas las observaciones y conteos fueron hechos durante el primer año de la colecta.

Se estimó la densidad del total de células de fitoplancton y se identificaron las especies/grupos, i.e. diatomeas, dinoflagelados tecados, cocolitofóridos y silicoflagelados. Se calculó el índice de diversidad de Shannon-Wiener para cada muestra, por especie y proporción (diversidad de especies). Se realizó 
immersion oil was added to clear the filter. They were then coverslipped and observed under a light microscope (LM), using bright field and total magnifications of $\times 600$ or $\times 1250$ to count or identify species, respectively (Bollmann et al. 2002). Preliminary species identification and cell counts were made using LM, estimating the number of cells per liter from data such as number of organisms counted, areas counted and filtered, and volume filtered, where the detection limits range between 300 and 3000 cells $\mathrm{L}^{-1}$ (Bollmann et al. 2002). Observations were also made by scanning electron microscopy (SEM) to confirm species identification, using small pieces of filters treated conventionally for SEM (Bollmann et al. 2002). Very few collapsed cells were found (because of the effect of changing $\mathrm{pH}$ or vacuum pressure). All observations and counts were made within one year of collection.

Total phytoplankton cell density was estimated and species/ groups were identified (i.e., diatoms, thecate dinoflagellates, coccolithophores, and silicoflagellates). The Shannon-Wiener diversity index was calculated for each sample, by species and ratio (species diversity). Cluster analysis was carried out to analyze similarities among stations. The resulting data that include environmental parameters affecting algal populations were square-root transformed to avoid the effect of the extreme values. Cluster analysis was undertaken using the PRIMER 6 (Plymouth Routines in Multivariate Ecological Research) computer software package, which achieves both transformation and standardization automatically; once a Pearson's productmoment correlation coefficient matrix is calculated, cluster analysis is performed using this matrix.

\section{Results}

\section{Physical environment}

Surface temperatures near the Grijalva-Usumacinta river system were between $25.75^{\circ} \mathrm{C}$ and $27.75^{\circ} \mathrm{C}$, decreasing offshore (fig. 2a). A weak thermal front was observed to the west of the mouth of this river system. Surface salinity varied from 36 to 37, increasing onshore (fig. 2b); maximum salinity was associated with high evaporation (Monreal-Gómez et al. 1992). In this study, surface salinity did not reflect the river plume nor the coastal haline front previously reported as a feature of this region (Monreal-Gómez et al. 1992). This coastal zone exhibits high salinities ( $>36$ ), but there was no detectable sharp boundary between river discharge and oceanic water, as observed in April 1984 by Czitrom et al. (1986). Sigma-t distribution showed a low-density offshore lens (fig. 2c) and a weak local front with waters from the eastern region. In the Coatzacoalcos River zone, surface temperature ranged from $25.25^{\circ} \mathrm{C}$ to $26.50^{\circ} \mathrm{C}$, increasing onshore (fig. 2a), and salinity varied between 35.80 and 36.20 , with lowest values close to the mouth (fig. 2b). Density ranged from 23.5 to $24.2 \mathrm{~kg} \mathrm{~m}^{-3}$, and its distribution was similar to that of temperature (fig. 2c). In the Campeche Canyon zone, the surface temperature, salinity, and density distributions remained very homogeneous, un análisis de conglomerados (cluster) con el fin de analizar la similitud entre estaciones. Los resultados, que incluyen parámetros ambientales que afectan la población algal, fueron transformados mediante su raíz cuadrada para evitar el efecto de los valores extremos. El análisis de conglomerados se efectuó usando el paquete de programas para computadora Plymouth Routines in Multivariate Ecological Research (PRIMER 6), el cual permite realizar la transformación y estandarización de los datos de forma automática; una vez que se calcula la matriz de los coeficientes de correlación del producto de los momentos se efectúa el análisis de conglomerados.

\section{Resultados}

\section{Características físicas}

La temperatura superficial cerca del sistema fluvial Grijalva-Usumacinta estuvo entre $25.75^{\circ} \mathrm{C}$ y $27.75^{\circ} \mathrm{C}$, decreciendo de la costa hacia el mar (fig. 2a). Se observó un débil

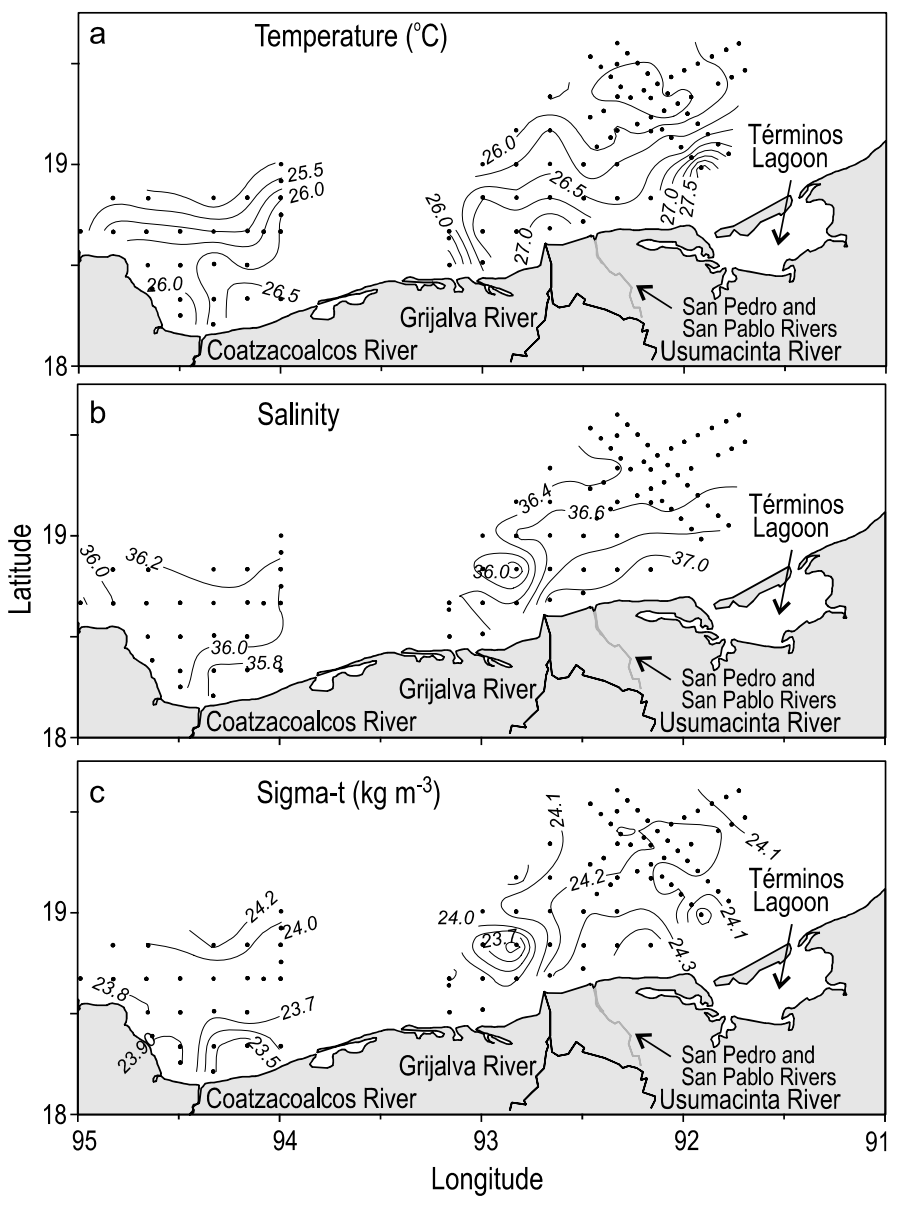

Figure 2. Coastal area. Surface contours of (a) temperature $\left({ }^{\circ} \mathrm{C}\right)$, (b) salinity, and (c) density $\sigma_{\mathrm{t}}\left(\mathrm{kg} \mathrm{m}^{-3}\right)$.

Figura 2. Área costera. Distribución superficial de: (a) temperatura $\left({ }^{\circ} \mathrm{C}\right),(\mathrm{b})$ salinidad y (c) densidad $\sigma_{\mathrm{t}}\left(\mathrm{kg} \mathrm{m}^{-3}\right)$. 
with values of about $26^{\circ} \mathrm{C}, 36.2$, and $24 \mathrm{~kg} \mathrm{~m}^{-3}$, respectively; thus, surface distribution data are not shown. The mixed layer was observed at a depth of $\sim 35 \mathrm{~m}$, and below this depth, at $40 \mathrm{~m}$, a horizontally distributed thermal front was observed.

During the study period, corresponding to early spring, vertical profiles exhibited weak haline stratification due to turbulence caused by strong winter winds (Salas-de León et al. 2004) (figs. 3-5). The seasonal thermocline developed offshore next to Campeche Canyon (fig. 5). The water column showed three patterns: (1) a shallow station (station 7, $50 \mathrm{~m}$ deep), very close to the coast, with homogeneous vertical temperature/salinity profiles and no thermocline, indicating a high degree of mixing; (2) coastal stations (stations 15, 22, 37, 44, and 53), with a weak thermocline between 30 and $35 \mathrm{~m}$; and (3) oceanic stations (stations 112, 118, and 126), with a thermocline between 35 and 45 m (figs. 3-5).

\section{Phytoplankton structure}

We identified 180 species as follows: 114 diatoms, 32 dinoflagellates (mostly thecate forms), 32 coccolithophores, and 2 silicoflagellates (table 1). A general view of the community revealed relatively high diversity and abundance of nanoplanktonic forms, mainly coccolithophores and both pennate and centric diatoms.

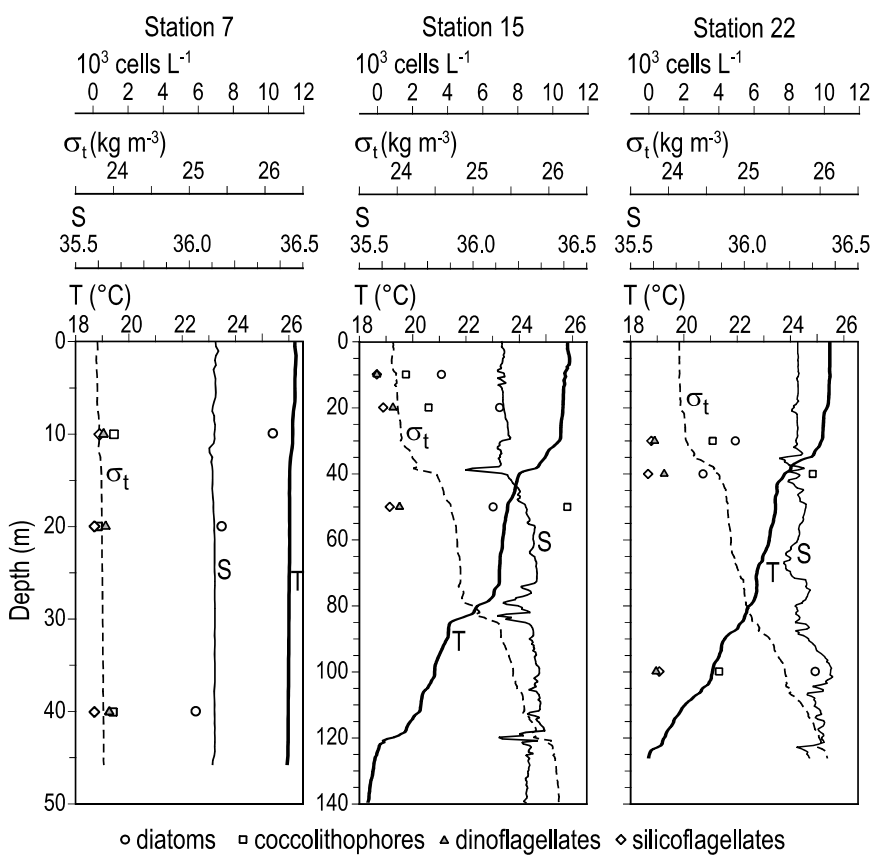

Figure 3. Vertical profiles of salinity, temperature $\left({ }^{\circ} \mathrm{C}\right)$, density $\sigma_{\mathrm{t}}\left(\mathrm{kg} \mathrm{m}^{-3}\right)$, and cell abundance (cells $\mathrm{L}^{-1}$ ), i.e., concentration of diatoms, coccolithophores, dinoflagellates, and silicoflagellates. Coastal zone (stations 7, 15, and 22) close to the Coatzacoalcos River.

Figura 3. Perfiles verticales de salinidad, temperatura $\left({ }^{\circ} \mathrm{C}\right)$, densidad $\sigma_{\mathrm{t}}(\mathrm{kg}$ $\mathrm{m}^{-3}$ ) y abundancia (cél $\mathrm{L}^{-1}$ ), i.e. concentración de diatomeas, cocolitoforidas, dinoflageladas y silicoflageladas. Zona costera (estaciones 7, 15 y 22) próxima al Río Coatzacoalcos. frente térmico al oeste de la boca de este sistema. La salinidad superficial varió de 36 a 37, incrementándose hacia la costa (fig. 2b); la salinidad máxima estuvo asociada con una gran evaporación (Monreal-Gómez et al. 1992). En este estudio, la salinidad superficial no reflejó la pluma fluvial ni el frente halino costero reportado previamente como una característica de la región (Monreal-Gómez et al. 1992). Esta zona costera muestra altas salinidades (>36), y no se detectó una frontera bien definida entre las aguas de la descarga de los ríos y el agua oceánica como la reportada para abril de 1984 por Czitrom et al. (1986). La distribución de sigma-t mostró lentes de baja densidad fuera de la costa (fig. 2c) y un débil frente local con aguas de la región del este. En la zona del Río Coatzacoalcos, la temperatura superficial varió de $25.25^{\circ} \mathrm{C}$ a $26.50^{\circ} \mathrm{C}$, incrementándose hacia la costa (fig. 2a), y la salinidad se observó entre 35.80 y 36.20 , con valores bajos cerca de la boca del río (fig. 2b). La densidad osciló entre 23.5 y $24.2 \mathrm{~kg} \mathrm{~m}^{-3}$, distribuida de manera similar a la temperatura (fig. 2c). En la zona del Cañón de Campeche, la temperatura, la salinidad y la densidad superficial permanecieron muy homogéneas, con valores alrededor de $26^{\circ} \mathrm{C}, 36.2$ y $24 \mathrm{~kg} \mathrm{~m}^{-3}$, respectivamente, por lo que no se muestran los gráficos correspondientes. La capa de mezcla se observó hasta una profundidad de $\sim 35 \mathrm{~m}$; abajo de esta profundidad, a $40 \mathrm{~m}$, se observó un frente térmico horizontal.

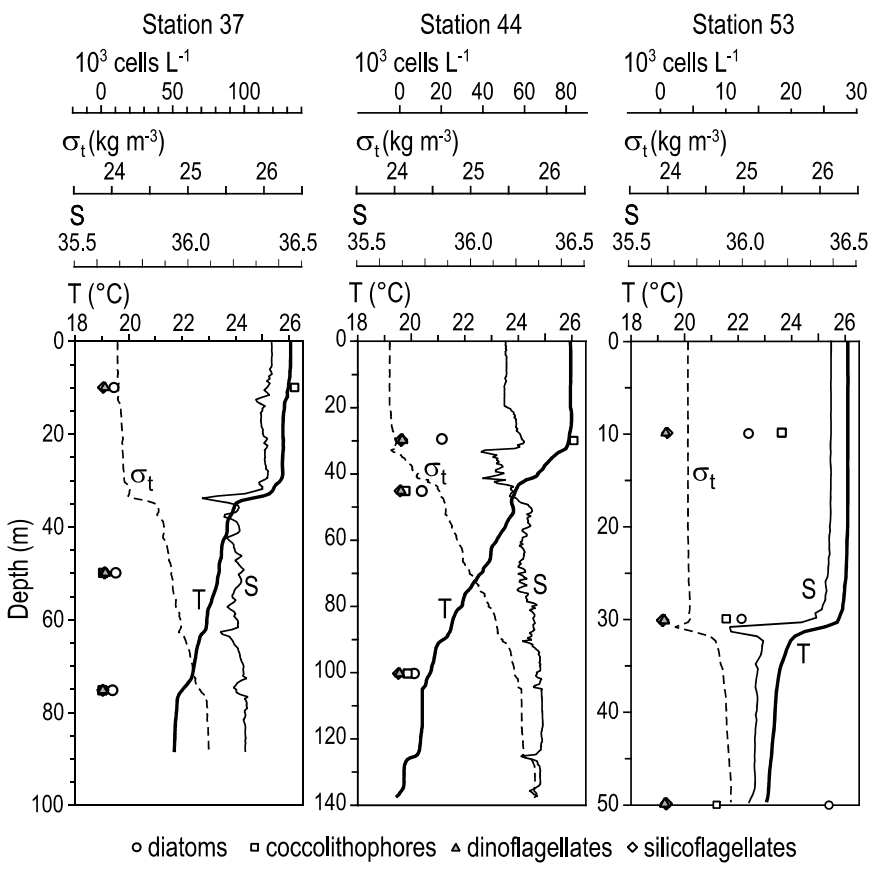

Figure 4. Vertical profiles of salinity, temperature $\left({ }^{\circ} \mathrm{C}\right)$, density $\sigma_{\mathrm{t}}\left(\mathrm{kg} \mathrm{m}^{-3}\right)$, and cell abundance (cells $\mathrm{L}^{-1}$ ), i.e., concentration of diatoms, coccolithophores, dinoflagellates, and silicoflagellates. Coastal zone (stations 37, 44, and 53) close to the Grijalva-Usumacinta river system.

Figura 4. Perfiles verticales de salinidad, temperatura $\left({ }^{\circ} \mathrm{C}\right)$, densidad $\sigma_{\mathrm{t}}(\mathrm{kg}$ $\mathrm{m}^{-3}$ ) y abundancia (cél $\mathrm{L}^{-1}$ ), i.e. concentración de diatomeas, cocolitoforidas, dinoflageladas y silicoflageladas. Zona costera (estaciones 37, 44 y 53) próxima al sistema fluvial Grijalva-Usumacinta. 


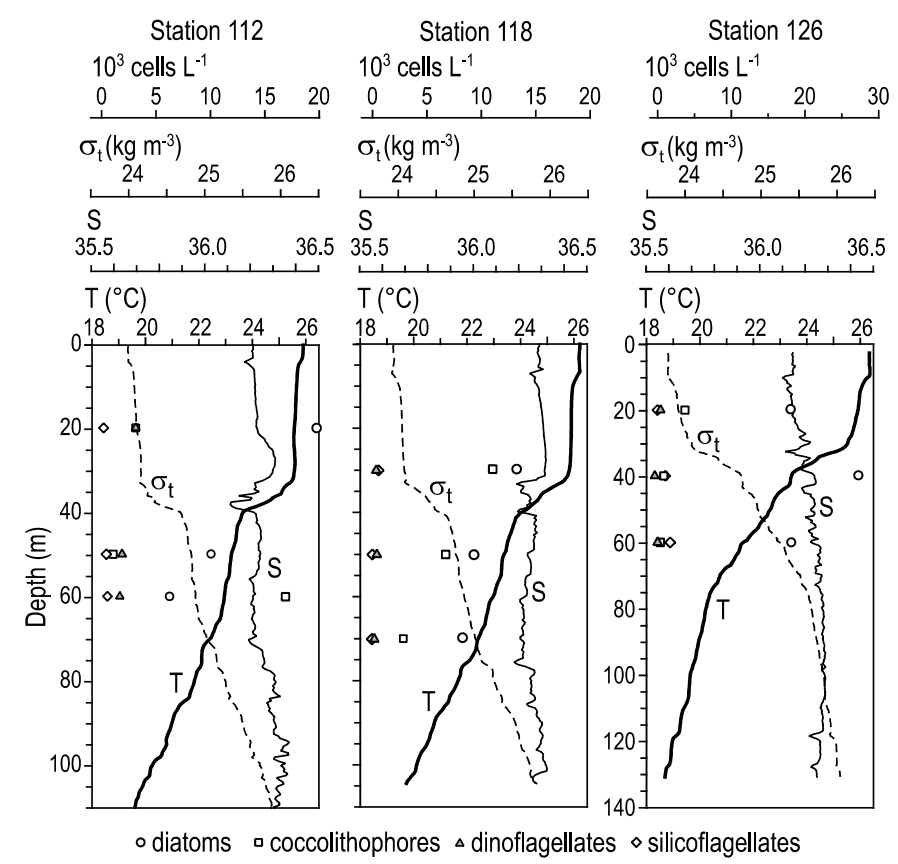

Figure 5. Vertical profiles of salinity, temperature $\left({ }^{\circ} \mathrm{C}\right)$, density $\sigma_{\mathrm{t}}\left(\mathrm{kg} \mathrm{m}^{-3}\right)$, and cell abundance (cells $\mathrm{L}^{-1}$ ), i.e., concentration of diatoms, coccolithophores, dinoflagellates, and silicoflagellates. Oceanic zone (stations 112, 118, and 126) over Campeche Canyon.

Figura 5. Perfiles verticales de salinidad, temperatura $\left({ }^{\circ} \mathrm{C}\right)$, densidad $\sigma_{\mathrm{t}}(\mathrm{kg}$ $\mathrm{m}^{-3}$ ) y abundancia (cél $\mathrm{L}^{-1}$ ), i.e. concentración de diatomeas, cocolitoforidas, dinoflageladas y silicoflageladas. Zona oceánica (estaciones 112, 118 y 126) sobre el Cañón de Campeche.

The phytoplankton was numerically dominated by coccolithophores and diatoms, with cell densities considered low to relatively high, ranging from $5.3 \times 10^{3}$ to $1.4 \times 10^{5}$ cells $\mathrm{L}^{-1}$ (table 2). There were no significant differences in abundance between the coastal and oceanic zones; however, highest densities were found in two subsurface samples from the same coastal area (10 m at station 37 and $30 \mathrm{~m}$ at station 44), comprising coccolithophores, which accounted for $85 \%$ of the total abundance (table 2).

The dominant species, in terms of numbers (table 2), were two coccolithophores, Emiliania huxleyi and Gephyrocapsa oceanica; the pennate diatoms Nitzschia bicapitata, $N$. bifurcata, and N. leehyi; and centric diatoms, Thalassiosira spp. All the diatoms were of small size $(<20 \mu \mathrm{m})$. Thecate dinoflagellates and silicoflagellates were rather scarce. At station 53, the abundance of Psammodictyon panduriforme, a benthic diatom, was also significant. Emiliania huxleyi and $N$. bifurcata were common forms in all samples, except at $50 \mathrm{~m}$ depth at station 37.

Diversity indices were highly heterogeneous, with values from 0.96 to 5.12 bits ind $^{-1}$. The lowest value (0.96), found at $10 \mathrm{~m}$ depth at station 37, where the dominant species was $E$. huxleyi, coincided with low species number and highest cell density (table 2). Conversely, the highest value (5.12),
En el periodo de investigación de este estudio, que corresponde al principio de la primavera, los perfiles verticales muestran una estratificación halina débil debido a la turbulencia causada por los fuertes vientos de invierno (Salas-de León et al. 2004) (figs. 3-5). La termoclina estacional se presenta de la costa hacia el mar en la zona próxima al Cañón de Campeche (fig. 5). La columna de agua mostró tres patrones: (1) estación somera (estación 7, 50 m de profundidad), muy próxima a la costa con perfiles verticales de temperatura y salinidad muy uniformes, sin termoclina, indicando un alto grado de mezcla; (2) estaciones costeras (estaciones 15, 22, 37, 44, y 53) con termoclina débil entre 30 y $35 \mathrm{~m}$; y (3) estaciones oceánicas (estaciones 112, 118 y 126) con termoclina entre 35 y 45 m (figs. 3-5).

\section{Estructura del fitoplancton}

Se identificaron 180 especies: 114 de diatomeas, 32 de dinoflagelados (la mayoría de formas tecadas), 32 de cocolitofóridos y dos de silicoflagelados (tabla 1). Una revisión rápida de la comunidad muestra una relativa alta diversidad y abundancia de las formas del nanoplancton, principalmente de cocolitofóridos y diatomeas pennadas y céntricas.

El fitoplancton estuvo numéricamente dominado por cocolitofóridos y diatomeas, con densidades de células de bajas a relativamente altas, de $5.3 \times 10^{3}$ a $1.4 \times 10^{5}$ cél L $^{-1}$ (tabla 2). No se encontraron diferencias significativas en las abundancia entre la zona costera y la oceánica; sin embargo, se encontraron las más altas densidades en dos muestras subsuperficiales, ambas en la zona costera (estaciones 37 a $10 \mathrm{~m}$ y 44 a $30 \mathrm{~m}$ ), conteniendo cocolitofóridos que representaron $85 \%$ de la abundancia total (tabla 2).

Las especies dominantes en términos numéricos (tabla 2) fueron dos cocolitofóridos, Emiliania huxleyi y Gephyrocapsa oceanica; las diatomeas pennadas, Nitzschia bicapitata, $N$. bifurcata, $N$. leehyi, y las diatomeas céntricas, Thalassiosira spp., todas diatomeas de tamaño pequeño $(<20 \mu \mathrm{m})$. Los dinoflagelados tecados y los silicoflagelados fueron escasos. En la estación 53 fue importante la abundancia de la diatomea béntica Psammodictyon panduriforme. Emiliania huxleyi y $N$. bifurcata se encontraron en todas las muestras, excepto en la estación 37 a $50 \mathrm{~m}$ de profundidad.

Los índices de diversidad fueron muy heterogéneos, con valores de 0.96 a 5.12 bits ind $^{-1}$. El valor más bajo (0.96), que se presentó en la estación 37 a 10 m (tabla 2), coincidió con un bajo número de especies y uno alto de células, siendo la especie dominante Emiliania huxleyi. Por el contrario, el valor más alto (5.12) coincidió con el número más alto de especies (47) y un número moderado de células, en la estación 22 a 100 m (tabla 2); muchas especies de diatomeas ticoplanctónicas contribuyeron significativamente en el gran número de especies en esta estación.

La distribución vertical de fitoplancton fue difícil de establecer, ya que la profundidad de las muestras fue diferente en la mayoría de las estaciones. Sin embargo, en la estación 
Table 1. List of species (diatoms, dinoflagellates, coccolithophores, and silicoflagellates) from the southern Gulf of Mexico (April 2000). The numbers correspond to the three zones studied: 1 = close to the Coatzacoalcos River (stations 7, 15, and 22); 2 = close to the Grijalva-Usumacinta river system (stations 37, 44, and 53); and $3=$ oceanic zone over Campeche Canyon (stations 112, 118, and 126).

Tabla 1. Lista de especies (diatomeas, dinoflageladas, cocolitoforidas y silicoflageladas) del sur del Golfo de México (abril del 2000). Los números corresponden a las tres zonas de estudio: 1 = cerca del Río Coatzacoalcos (estaciones 7, 15, 22), 2 = cerca del sistema fluvial Grijalva-Usumacinta (estaciones 37, 44, 53), 3 = zona oceánica sobre el Cañón de Campeche (estaciones 112, 118, 126).

\section{Diatoms (Bacillariophycea)}

Achnanthes lacunarum Hustedt

Achnanthes longipes Agardh

Actinocyclus octonarius Ehrenberg

Actinoptychus senarius (Ehr.) Ehrenberg

Amphora ovalis Kützing

Amphora sp.

Asteromphalus heptactis (Bréb.) Ralfs

Asteromphalus sarcophagus Wallich

Azpetia nodulifera (Schm.) Fryxell \& Sims

Bacillaria paxillifera (Müller) Hendey

Bacteriastrum delicatulum Cleve

Bacteriastrum furcatum Shadbolt

Bleakeleya notata (Grunow) Round

Catacombas gaillonii (Bory) Will. \& Round

Chaetoceros affinis Lauder

Chaetoceros atlanticus Cleve

Chaetoceros bacteriastroides Karsten

Chaetoceros compressus Lauder

Chaetoceros decipiens Cleve

Chaetoceros didymus Ehrenberg

Chaetoceros diversus Cleve

Chaetoceros lorenzianus Grunow

Chaetoceros messanensis Castracane

Chaetoceros mitra (Bailey) Cleve

Chaetoceros peruvianus Brightwell

Chaetoceros sp.

Cocconeis scutellum Ehrenberg

Coscinodiscus asteromphalus Ehrenberg

Coscinodiscus centralis Ehrenberg

Coscinodiscus radiatus Ehrenberg

Cyclotella meneghiniana Kützing

Cyclotella striata (Kützing) Grunow

Cyclotella stylorum Brightwell

Cyclotella sp.

Cylindrotheca closterium (Ehrenberg) Reimann \& Lewin

Cymatosira lorenziana Grunow

Delphineis surirella (Ehrenberg) Andrews

Diploneis bombus Ehrenberg

Diploneis sp.

Fragilaria brevistriata (Grunow) Grunow

Fragiloriopsis pseudonana (Hasle) Hasle

Gyrosigma fasciola (Ehrenberg) Griffith \& Henfrey
3

1

1,2

1,2

$1,2,3$

1, 2

1, 2, 3

2, 3

3

1, 2, 3

1, 2, 3

2

1

1, 2

2

2

2, 3

1, 2, 3

1, 2, 3

2, 3

2

2, 3

1, 2, 3

2

1, 2, 3

1, 2, 3

1,3

1, 2, 3

2

2

1, 2

1, 2

1, 2, 3

1

1, 2

1

1, 3

1, 2, 3

1

1, 3

1, 2, 3

3
Haslea frauenfeldii (Grunow) Simonsen

3

Hemiliaulus sinensis Greville

$1,2,3$

Lauderia annulata Cleve

3

1,2

Licmophora flabellata (Carmichel) Agardh

Licmophora abreviata Agardh

Licmophora sp.

Lioloma delicatulum (Cupp) Hasle

Lithodesmium undulatum Ehrenberg

Mastogloia gibbosa Brun

Mastogloia pusilla Östrup

Navicula directa (Smith) Ralfs

Navicula distans (Smith) Ralfs

Navicula gastrum (Ehrenberg) Kützing

Navicula grimmei Krasske

Navicula halophila (Grunow) Cleve

Navicula lanceolata (Agardh) Kützing

Navicula pelliculosa (Brébisson) Hilse

Navicula platyventris Meister

Navicula regularis Hustedt

Navicula soehrensis Krasske

Navicula sp. 1

Navicula sp. 2

Nitzschia bicapitata Cleve

Nitzschia bifurcata Kaczmarska \& Licea

Nitzschia longissima (Brébisson) Ralfs

Nitzschia ovalis Arnott in Cleve \& Grunow

Nitzschia frustulum (Kützing) Grunow

Nitzschia dissipata (Kützing) Grunow

Nitzschia gardersheimiensis Krasse

Nitzschia kolaczeckii Grunow

Nitzschia leehyi Fryxell

Nitzschia sicula (Castracane) Hustedt

Nitzschia sp.

Odontella aurita (Lyngbye) Agardh

Odontella rhombus (Ehr.) Kützing

Opephora marina (Gregory) Petit

Paralia sulcata (Ehrenberg) Cleve

Pleurosigma angulatum (Quekett) Smith

Pleurosigma diverse-striata (Meist.) Hend.

Pleurosigma sp.

Proboscia alata (Brightwell) Sundström

Psammodictyon panduriforme (Greg.) Mann
1

1

2

2

1

1

1

1, 2

1

1

1

1

1

1

1, 2

1

1, 2

1, 2

1, 2, 3

$1,2,3$

1, 2

2

1, 2

1

1, 2

1, 3

1, 2, 3

1, 2, 3

2

1

2

1

2, 3

1

1, 2, 3

1, 2, 3

1, 2, 3

1, 2 


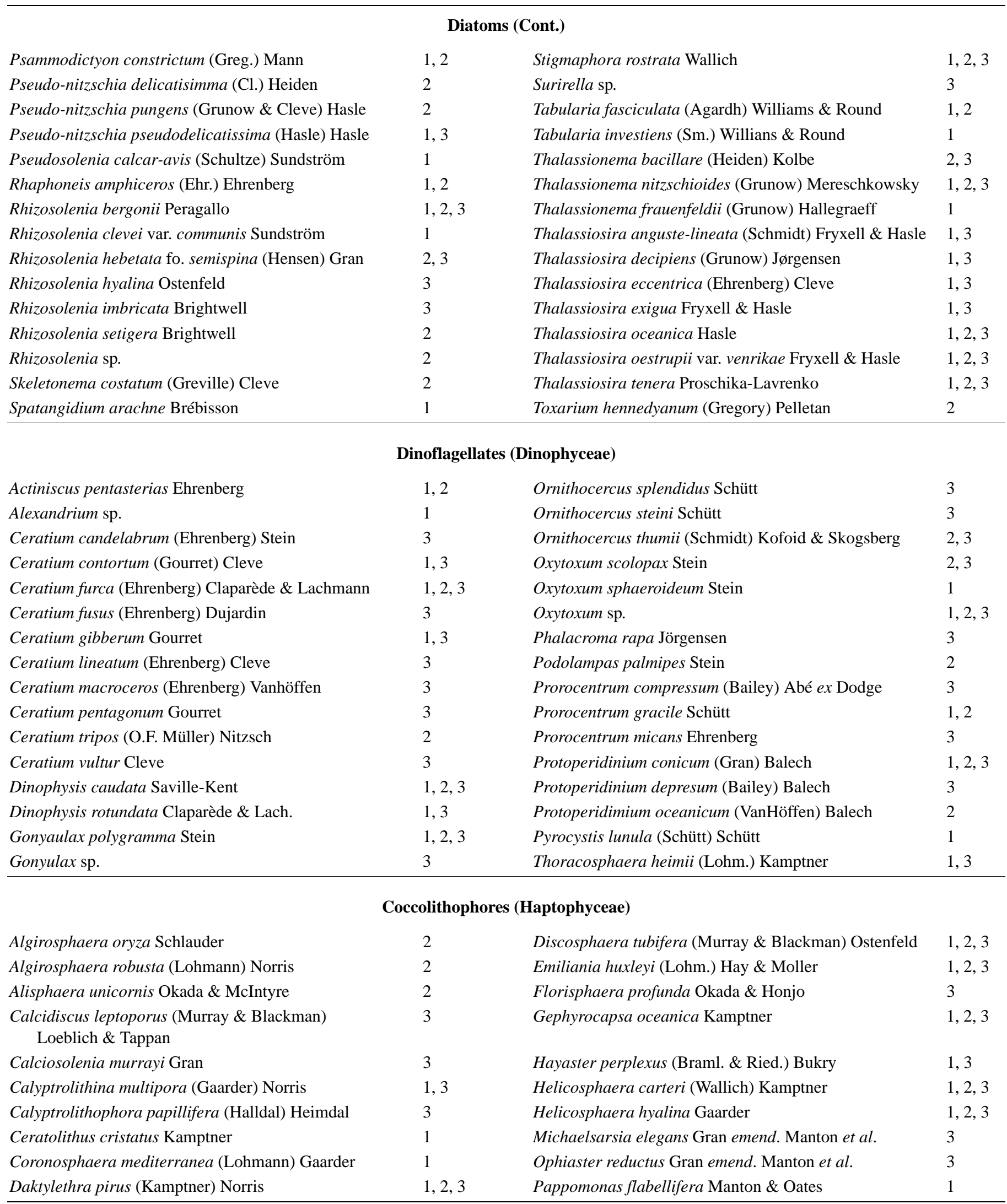




\section{Coccolithophores (Cont.)}

Periphyllophora mirabilis (Schiller) Kampt.

Pontosphaera discopora Schiller

Pontosphaera syracusana Lohmann

Rhabdosphaera clavigera Murr. \& Black.

Rhabdosphaera xiphos (Deflandre \& Fert) Norris

Syracolithus dalmaticus (Kamptner) Loeblich \& Tappan
1

1,3

1,3

$1,2,3$

1

3
Syracolithus catilliferus (Kampt.) Deflandre

1,2

Syracosphaera orbiculus Okada \& McInt.

$1,2,3$

$1,2,3$

$1,2,3$

$1,2,3$

1,3

\section{Silicoflagellates (Dictyochophyceae)}

$1,2,3$

Dictyocha octonaria Ehrenberg

$1,2,3$

Table 2. Parameters of phytoplankton structure in the southern Gulf of Mexico.

Tabla 2. Parámetros de la estructura del fitoplancton en el sur del Golfo de México.

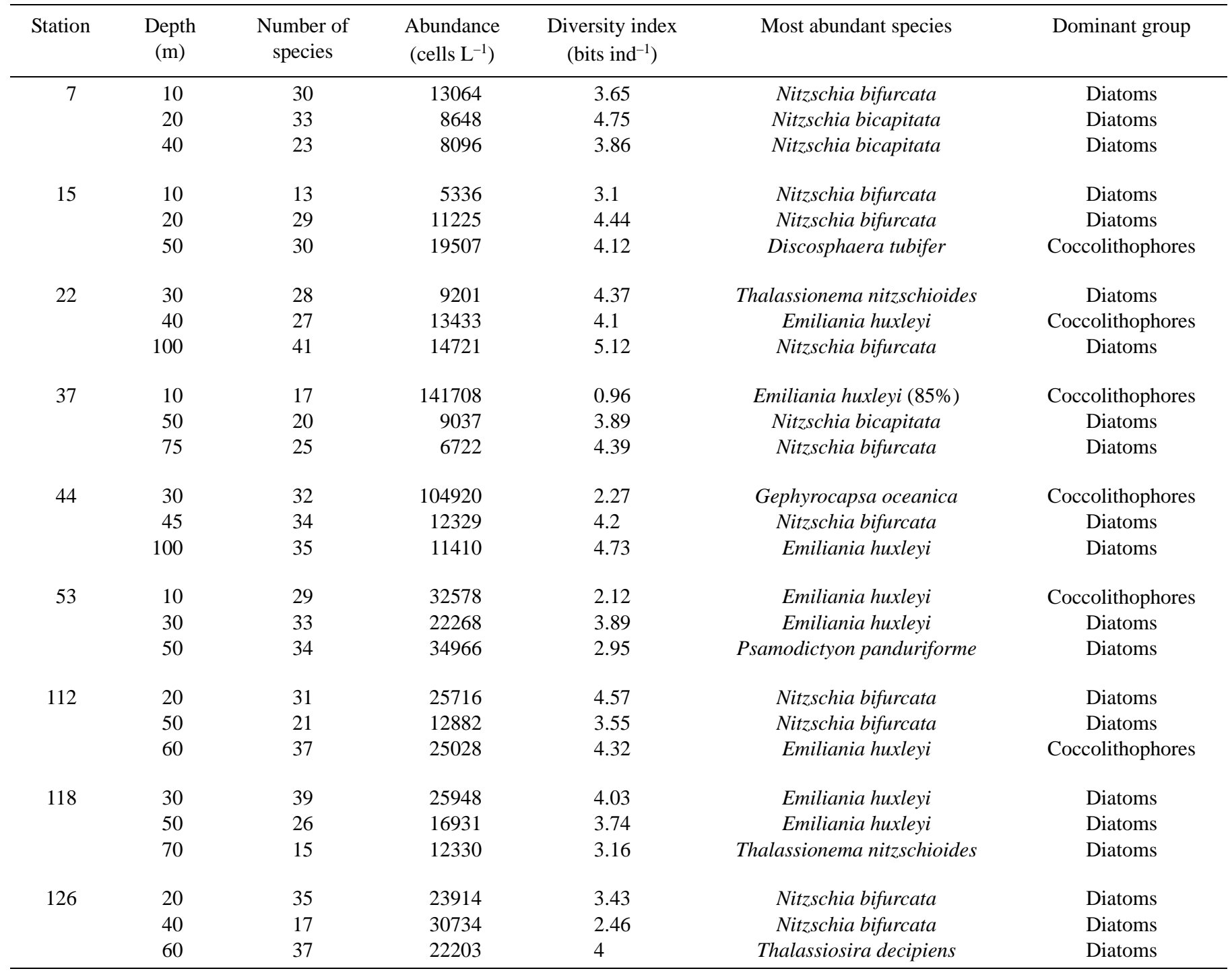




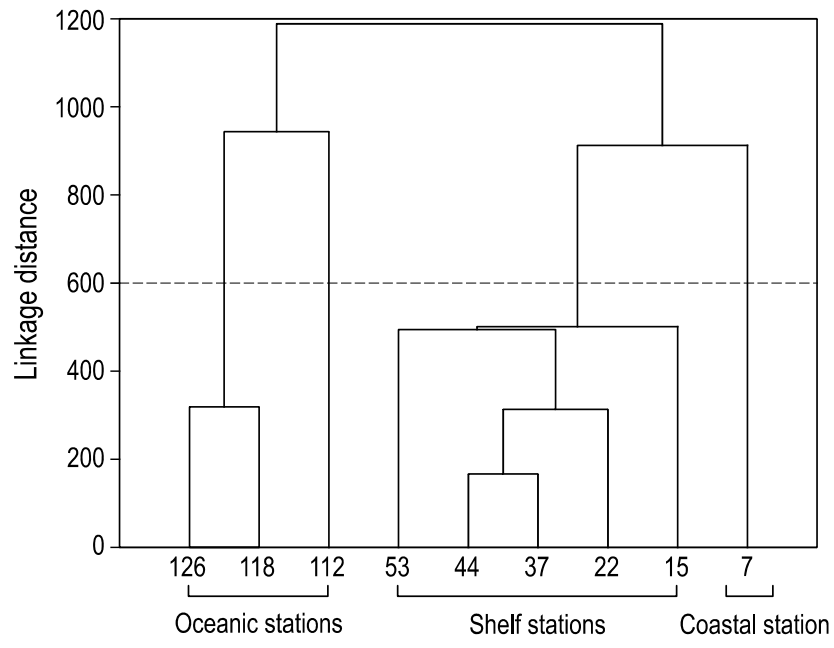

Figure 6. Tree diagram showing Euclidean distances and similarities among stations according to hydrographic parameters, and species composition and abundance (see table 2).

Figura 6. Diagrama de conglomerados que muestra las distancias Euclideanas y la similitud entre estaciones de acuerdo a los parámetros hidrográficos y la composición y abundancia de especies (ver tabla 2).

recorded at $100 \mathrm{~m}$ depth at station 22, coincided with the highest species number (47) and moderate cell density (table 2). Many tychoplanktonic diatom species contributed to the higher species number at this station.

Vertical distribution of phytoplankton was difficult to elucidate, especially as sampling depths varied at most stations. However, at shallow station 7, with a well-mixed water column, phytoplankton, especially diatoms, showed a homogeneous distribution. At station 44, the highest phytoplankton cell density coincided with the depth of the thermocline (fig. 4).

\section{Station association}

Cluster analysis identified three regions: oceanic, shelf and coastal (fig. 6). Station 7 appeared isolated, possibly because it is the shallowest station with a slightly different species composition. Over the continental shelf, all stations composed a single group; stations 37 and 44 were very close, indicating similar species composition, most probably due to the high abundance of the coccolithophore fraction at these stations (table 2, fig. 6). Stations 118 and 126 over Campeche Canyon were also clustered, probably due to the dominant groups.

Temperature is the main factor affecting the variance in species number, while salinity is the main factor affecting the variance of dominant groups.

\section{Discussion}

At the beginning of April 2000, the flow of the Grijalva, Usumacinta and Coatzacoalcos rivers was quite low (RiverónEnzástiga 2008). During this month, a characteristic northerly poco profunda (7), con una columna de agua bien mezclada, el fitoplancton mostró una distribución homogénea, especialmente las diatomeas. En la estación 44 el máximo en la densidad de células coincidió con la profundidad de la termoclina (fig. 4).

\section{Asociación entre estaciones}

Mediante el análisis de conglomerados se identificaron tres regiones: costera, de plataforma y oceánica (fig. 6). La estación 7 apareció aislada, posiblemente por que ésta es la estación más somera con una composición de especies ligeramente diferente. Sobre la plataforma continental las estaciones formaron un grupo: las estaciones 37 y 44 fueron muy cercanas en el análisis de conglomerados, lo que indica una composición de especies muy similar, probablemente debido a la gran abundancia de la fracción de cocolitofóridos en estas estaciones (tabla 2, fig. 6). Las estaciones 118 y 126, sobre el Cañón de Campeche, también resultaron muy cercanas debido probablemente a la similitud de sus grupos dominantes.

La temperatura resultó el factor más importante en la varianza del número de especies, mientras que la salinidad fue el factor que más influyó en la varianza de los grupos dominantes.

\section{Discusión}

Al principio de abril de 2000, el flujo de la descarga de los ríos Coatzacoalcos y Grijalva-Usumacinta fue baja (RiverónEnzástiga 2008). Durante este mes, los vientos característicos provenientes del norte en la Bahía de Campeche, confinaron la pluma de los ríos hacia la costa. Debido a la reducida descarga, la pluma del Coatzacoalcos se constriñó a la zona costera cercana a la boca, resultando en un ambiente oceánico (Salas-de León et al. 1998). La zona costera próxima al sistema GrijalvaUsumacinta no mostró una frontera muy marcada entre la descarga de los ríos y el agua oceánica, como la reportada en varios trabajos anteriores (Czitrom et al. 1986, MonrealGómez et al. 1992). En la zona del Cañón de Campeche la capa superficial permaneció muy homogénea. Los altos valores de salinidad en las tres zonas indican condiciones oceánicas.

La abundancia de fitoplancton observada durante este estudio no fue particularmente alta; la densidad más alta fue de 1.4 $\times 10^{5}$ cél $\mathrm{L}^{-1}$. Licea y Luna (1999) reportan valores mayores (4.14 × $10^{5}$ cél $\mathrm{L}^{-1}$ ) durante la misma estación (febrero a marzo) frente a los ríos Coatzacoalcos y Grijalva-Usumacinta; mientras que en la estación de lluvias (julio a agosto) los valores máximos reportados por estos autores son de $6.3 \times 10^{6}$ cél $\mathrm{L}^{-1}$. El número de especies y el índice de diversidad mostraron una fuerte relación, especialmente en la estación 22 a $100 \mathrm{~m}$, donde coincidieron los valores máximos del número de especies y del índice de diversidad (tabla 2). Los valores de diversidad de especies fueron similares a los reportados por Licea y Santoyo (1991) para la región central de la Bahía de Campeche. 
wind in the Bay of Campeche confines the river plumes to the coast. Owing to the lower flow of the Coatzacoalcos River, its plume is constricted to the coastal zone near the mouth of the river, resulting in an oceanic environment (Salas-de León et al. 1998). However, the Grijalva-Usumacinta coastal zone did not exhibit a sharp boundary between river discharge and oceanic water, as reported previously (Czitrom et al. 1986, MonrealGómez et al. 1992). At Campeche Canyon, the surface layer remained very homogeneous. The high salinity values in these three zones indicate oceanic conditions.

Phytoplankton abundance may not be considered particularly high (highest density was $1.4 \times 10^{5}$ cells $\mathrm{L}^{-1}$ ). Licea and Luna (1999) recorded higher values (up to $4.14 \times 10^{5}$ cells $\mathrm{L}^{-1}$ ) during the same season (February-March) off the Coatzacoalcos and Grijalva-Usumacinta river systems, and much higher values (maximum $6.3 \times 10^{6}$ cells $\mathrm{L}^{-1}$ ) during the rainy season (July-August). Certain parameters, such as number of species and diversity indices, showed a close relationship, especially at station 22 at $100 \mathrm{~m}$ depth, where the highest number of species and diversity index value were found (table 2). Species diversity values were similar to those reported by Licea and Santoyo (1991) for a central area of the Bay of Campeche.

The most conspicuous species, Emiliania huxleyi, Nitzschia bicapitata and Thalassionema nitzschioides, are considered cosmopolitan. Coastal species assemblages found in this study may be typical of mature upwelled waters (Mitchell-Innes and Winter 1987), which are dominated in numbers by nanoplanktonic species: coccolithophores and diatoms. This may also be interpreted in terms of phytoplankton community succession, as part of stage 2, where mixed assemblages of coccolithophores and small- and medium-sized diatoms are important contributors to the community (Margalef 1958, 1974; Smayda 1980; Reynolds 1995). We believe that the "normal" pattern of succession might be modified if oceanographic or climatic events occur locally (i.e., fronts, turbulence, strong winds, heavy rains, etc.).

The association between E. huxleyi and Gephyrocapsa oceanica has been previously reported for the southern Gulf of Mexico by Hulburt and Corwin (1972), and the associations between these two coccolithophores and the diatoms $N$. bicapitata, $N$. bifurcata, and $N$. leehyi has also been observed in Mexican Pacific waters during the last stage of the 19971998 El Niño event (Hernández-Becerril et al. 2007), and in the Equatorial Pacific (Lee and Fryxell 1996, Fryxell 2000). At some stations (where samples were taken very close to the sea bottom), the contribution of non-planktonic diatoms, such as Psammodictyon panduriforme, was considerable, significantly modifying the species assemblages (station 22 at $50 \mathrm{~m}$ depth and station 53 at $100 \mathrm{~m}$ depth) (table 2).

Different water column patterns were defined (i.e., presence and depth of thermoclines) and, consequently, the phytoplankton showed differences in community structure, especially species composition and abundance. As opposed to the horizontal path where the maximum abundances were associated with the thermal front, no general patterns were found in
Las especies sobresalientes: Emiliania huxleyi, Nitzschia bicapitata y Thalassionema nitzschioides, son consideradas cosmopolitas. Las asociaciones de especies costeras encontradas en este estudio pueden ser indicadoras de aguas de surgencia maduras (Mitchell-Innes y Winter 1987), las cuales fueron en su mayoría especies nanoplanctónicas: cocolitofóridos y diatomeas. Esto puede interpretarse también, en términos de sucesión de comunidades de fitoplancton, como parte del estadio 2, donde una mezcla entre asociaciones de cocolitofóridos con diatomeas de pequeño y mediano tamaño contribuye de forma importante a la comunidad (Margalef 1958, 1974; Smayda 1980, Reynolds 1995). Consideramos que el patrón 'normal' de sucesión puede modificarse al ocurrir eventos oceanográficos o climáticos locales importantes (i.e. frentes, turbulencia, vientos fuertes, lluvias intensas, etc.).

La asociación entre Emiliania huxleyi y Gephyrocapsa oceanica fue reportada en el Golfo de México por Hulburt y Corwin (1072), y la asociación entre estos dos cocolitofóridos y las diatomeas Nitzschia bicapitata/N. bifurcata/N. leehyi también fue reportada en aguas del Pacífico Mexicano hacia el final del evento de El Niño de 1997-1998 (Hernández-Becerril et al., 2007) y en el Pacífico ecuatorial (Lee y Fryxell 1996, Fryxell 2000). En algunas estaciones (i.e. muestras tomadas muy cerca del fondo) la contribución de las diatomeas no planctónicas tales como Psammodictyon panduriforme fue considerable, modificando significativamente las asociaciones de especies (estación 22 a 50 m y estación 53 a 100 m) (tabla 2).

Se definieron diferentes patrones en la columna de agua (i.e. presencia y profundidad de la termoclina) y, consecuentemente, el fitoplancton mostró diferencias en la estructura de la comunidad, especialmente en la abundancia y composición de especies. No se encontraron patrones generales en la distribución vertical de la comunidad del fitoplancton tales como máximo de células de fitoplancton asociados a la termoclina principal, distribución vertical más o menos homogénea, o la presencia de un máximo subsuperficial $(10 \mathrm{~m})$ de densidad de células, lo que resulta contrario al patrón horizontal en donde las máximas abundancias estuvieron asociadas al frente térmico. Sin embargo, se pudieron observar algunas tendencias en la distribución vertical de ciertos grupos taxonómicos. Los cocolitofóridos fueron más abundante y también dominaron numéricamente en algunas capas subsuperficiales (i.e. 40-60 $\mathrm{m}$; estaciones 15, 22, 112). De hecho, el número de éstas aumenta cerca de la termoclina (estaciones 15, 22; tabla 2 y figs. 3-5), igual a lo que ocurre en otras áreas del mundo (i.e. Golfo de California; Hernández-Becerril 1987). En general, se considera que el número de los cocolitofóridos aumenta de la capa subsuperficial hacia las aguas profundas (Margalef 1978, Brand 1994, Balch 2004). En este estudio las excepciones fueron las estaciones costeras 37 y 44, donde dos especies de este grupo, Emiliania huxleyi y Gephyrocapsa oceanica, tuvieron altas densidades a 10 y $30 \mathrm{~m}$ de profundidad, respectivamente, y contribuyeron numéricamente al fitoplancton con más del 75\% (tabla 2). Las densidades de cocolitofóridos 
the typical vertical distribution of the total phytoplankton community (maximum cell density associated with the main thermocline, vertical distribution more or less homogeneous, or the presence of a higher maximum subsurface cell density at $10 \mathrm{~m})$.

On the other hand, some trends were observed in the vertical distribution of certain taxonomic groups. Coccolithophores were more abundant and even numerically dominant in some subsurface layers (40-60 $\mathrm{m}$ at stations 15,22 , and 112). In fact, they increased their numerical contribution close to the thermocline (stations 15 and 22; table 2, figs. 3-5), as also observed in the Gulf of California (Hernández-Becerril 1987). Coccolithophores are believed to be distributed more densely from subsurface to deeper waters (Margalef 1978, Brand 1994, Balch 2004). In this study exceptions were found at coastal stations 37 and 44, where two species of this group, E. huxleyi and G. oceanica, had higher densities at depths of 10 and $30 \mathrm{~m}$, respectively, and contributed $>75 \%$ to phytoplankton numbers (table 2). The coccolithophore densities observed should not be considered algal blooms (according to Tyrrell and Merico 2004 they should start at densities of $1 \times 10^{6}$ cells L $^{-1}$ ), which occur in other regions of the world (Brown and Yoder 1994, Balch 2004) but have not yet been documented for the southern Gulf of Mexico. At $45 \mathrm{~m}$ depth at station 44, phytoplankton density diminished considerably and diatoms became dominant (table 2, fig. 4).

Diatoms have traditionally been considered the dominant group (both in number and diversity) in coastal, turbulent, and nutrient-rich areas, not only in the Gulf of Mexico, but worldwide. In this study, they were represented by nanoplanktonic pennate and centric forms.

The nanoplankton fraction (coccolithophores and other small nanoalgae) has usually been underestimated in the southern Gulf of Mexico. Many studies have traditionally considered the microplankton fraction, especially large diatoms and dinoflagellates (Balech 1967, Licea 1994, Hernández-Becerril and Flores 1998, Licea et al. 2004), as the major contributors to primary production.

Licea and Luna (1999) reported high chlorophyll $a$ values (1.6 $\mathrm{mg} \mathrm{m}^{-3}$ ) for winter (February-March) in the GrijalvaUsumacinta river fronts at $20 \mathrm{~m}$ depth, which is the same area and depth where high coccolithophore densities were found in our study.

The predominant circulation pattern near the coastal zone was anticyclonic, whereas in the Campeche Canyon zone it was cyclonic (http://www.ccar.colorado.edu/pub/gom/nrt/gif/). The boundaries or interfaces between cyclonic-anticyclonic eddies and frontal areas enhance primary production via nutrient input (Biggs and Müller-Karger 1994, Toner et al. 2003, Barocio-León et al. 2007). Additionally, it has been proposed that high phytoplankton production on the shelf is promoted by river plumes in the southern Gulf of Mexico, with changes in phytoplankton structure (Licea and Luna 1999).

In this study, nanoplankton, mainly coccolithophores, were found to play an important role in the structure of the observadas no pueden ser consideradas como resultado de florecimientos algales, ya que de acuerdo con Tyrrell y Merico

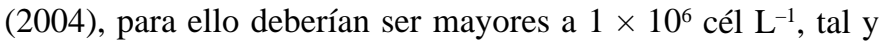
como ocurre en otras regiones del mundo (Brown y Yoder 1994, Balch 2004); sin embargo, estos florecimientos todavía no han sido reportados en el sur del Golfo de México. En la estación 44 a $45 \mathrm{~m}$ de profundidad, la densidad de fitoplancton disminuye considerablemente $\mathrm{y}$ dominaron las diatomeas (tabla 2 y fig. 4).

En general, en áreas costeras con aguas turbulentas y ricas en nutrientes, las diatomeas han sido tradicionalmente consideradas como el grupo dominante (tanto en número como en densidad). En este estudio, éstas estuvieron representadas por las formas nanoplanctónicas pennadas y céntricas.

La fracción del nanoplancton (cocolitofóridos y otras nanoalgas pequeñas) usualmente ha sido subestimada para el sur del Golfo de México. Varios estudios consideran tradicionalmente a la fracción del microplancton, especialmente las diatomeas y los dinoflagelados grandes (Balech 1967, Licea 1994, Hernández-Becerril y Flores 1998, Licea et al. 2004), como las que más contribuyen en la producción primaria.

Licea y Luna (1999) reportan altos valores de clorofila $a$ (1.6 $\mathrm{mg} \mathrm{m}^{-3}$ ) para invierno (febrero-marzo) en el frente del sistema fluvial Grijalva-Usumacinta a $20 \mathrm{~m}$ de profundidad, coincidiendo con el área y la profundidad en donde se encontraron altas densidades de cocolitofóridos en este trabajo.

El patrón de la circulación predominante en la zona costera fue anticiclónico, mientras que en la región del Cañón de Campeche fue ciclónico (http://www.ccar.colorado.edu/pub/ gom/nrt/gif/). Las fronteras o interfaces entre los giros ciclóni$\cos$ y anticiclónicos y las regiones frontales promueven la producción primaria mediante el aporte de nutrientes (Biggs y Müller-Karger 1994, Toner et al. 2003, Barocio-León et al. 2007). Adicionalmente, se ha propuesto que la alta producción fitoplanctonica sobre la plataforma continental es promovida por la pluma de los ríos en el sur del Golfo de México, con cambios en la estructura fitoplanctónica (Licea y Luna 1999).

En este estudio se encontró que el nanoplancton, especialmente los cocolitofóridos, juegan un papel importante en la estructura de las comunidades del fitoplancton en el sur del Golfo de México durante la primavera. La estructura de la comunidad del fitoplancton estuvo relacionada con las condiciones oceanográficas. Las mayores abundancias de fitoplancton, principalmente dominadas por dos especies de cocolitofóridos, estuvieron asociadas a un frente térmico. La diferencia en las condiciones oceanográficas entre las zonas costeras, de plataforma y oceánica, se reflejó en la estructura del fitoplancton, especialmente en la composición de las especies. Quedan preguntas sin responder en relación a cómo los procesos hidrodinámicos controlan la estructura de la comunidad del fitoplancton en el sur del Golfo de México a lo largo del año. En trabajos futuros se debe hacer énfasis en el estudio de las sucesiones y estacionalidad del fitoplancton, especialmente del nanoplancton y el picoplancton en el área de estudio. 
phytoplankton communities in the southern Gulf of Mexico during spring. Phytoplankton community structure was related to prevalent oceanographic conditions. The highest phytoplankton abundance, mainly dominated by two coccolithophore species, was associated with a thermal front. The different oceanographic conditions in the coastal, shelf, and oceanic zones were reflected in the phytoplankton structure, especially in species composition. Unanswered questions remain regarding the hydrodynamic processes that control the structure of the phytoplankton community in the southern Gulf of Mexico throughout the year. Future work should emphasize succession and seasonality of phytoplankton, especially nanoplankton and picoplankton, in the study area.

\section{Acknowledgements}

This study was supported by the Mexican Council for Science and Technology (CONACYT) through project G27777-B, and JA García-Reséndiz acknowledges receipt of a fellowship under the same grant. We thank the captain and crew of the R/V Justo Sierra for their help, and J Castro for assistance in preparing the figures. We especially thank the reviewers for their comments and suggestions that helped to significantly improve this paper.

\section{References}

Balch WM. 2004. Re-evaluation of the physiological ecology of coccolithophores. In: Thierstein H, Young J (eds.), Coccolithophores: From Molecular Processes to Global Impact. Springer-Verlag, Berlin, pp. 65-190.

Balech E. 1967. Dinoflagelados nuevos o interesantes del Golfo de México y Caribe. Rev. Mus. Argent. Cienc. Nat. Bernardino Rivadavia (Hidrobiol.) 2: 77-144.

Barocio-León OA, Millán-Núñez R, Santamaría-del-Ángel E, González-Silveira A. 2007. Phytoplankton primary productivity in the euphotic zone of the California Current System estimated from CZCS imagery. Cienc. Mar. 33: 59-72.

Biggs DC, Müller-Karger FE. 1994. Ship and satellite observations of chlorophyll stocks in interacting cyclonic-anticyclonic eddy pairs in the western Gulf of Mexico. J. Geophys. Res. 99: 7371-7384.

Bollmann J, Cortés MY, Haidar AT, Brabec B, Close A, Hofmann R, Palma S, Tupas L, Thierstein HR. 2002. Techniques for quantitative analyses of calcareous marine phytoplankton. Mar. Micropaleontol. 44: 163-185.

Brand LE. 1994. Physiological ecology of marine coccolithophores. In: Winter A, Siesser WG (eds.), Coccolithophores. Cambridge Univ. Press, New York, pp. 39-49.

Brown CW, Yoder JA. 1994. Coccolithophorid blooms in the global ocean. J. Geophys. Res. 99: 7467-7482.

Cruz de la A. 1971. Estudios de plancton en el Banco de Campeche. In: Coloquio sobre Investigaciones y Recursos del Mar Caribe y Regiones Adyacentes. UNESCO, Paris, pp. 375-383.

Czitrom SPR, Ruiz F, Alatorre MA, Padilla AR. 1986. Preliminary study of a front in the Bay of Campeche, Mexico. In: Nihoul JCJ (ed.), Marine Interfaces Ecohydrodynamics. Elsevier, Amsterdam, pp. 301-311.

Fofonoff NP, Millard Jr RC. 1983. Algorithms for computation of fundamental properties of seawater. UNESCO Tech. Pap. Mar. Sci. 44: 53 pp.

\section{Agradecimientos}

Se agradece el apoyo recibido por el Consejo Nacional de Ciencia y Tecnología de México (CONACYT) mediante el proyecto G27777-B. JA García-Reséndiz recibió una beca de este proyecto. Se agradece el apoyo del capitán y la tripulación del B/O Justo Sierra de la UNAM durante la campaña oceanográfica PROMEBIO III, y a Jorge Castro por el apoyo en la preparación del material gráfico. También se agradecen los comentarios y sugerencias de los revisores, los cuales mejoraron sustancialmente este artículo.

Fryxell GA. 2000. Nitzschia bicapitata (Bacillariophyceae) and related taxa from oceanic aggregations. Diat. Res. 15: 43-73.

Furnas MJ, Smayda TJ. 1987. Inputs of subthermocline waters and nitrate onto the Campeche Bank. Cont. Shelf Res. 7: 161-175.

Gaarder KR, Hasle GR. 1971. Coccolithophorids of the Gulf of Mexico. Bull. Mar. Sci. 21: 519-544.

Hernández-Becerril DU. 1987. Vertical distribution of phytoplankton in the central and northern part of the Gulf of California (June, 1982). Mar. Ecol. 8: 237-251.

Hernández-Becerril DU. 1998. Morphological study of the marine planktonic diatom Chaetoceros okamurai (Chaetocerotales, Bacillariophyceae) from the Gulf of Mexico. Phycol. Res. 46: 1115.

Hernández-Becerril DU, Flores C. 1998. Species of the diatom genus Chaetoceros (Bacillariophyceae) in the plankton from the southern Gulf of Mexico. Bot. Mar. 41: 505-519.

Hernández-Becerril DU, Bravo-Sierra E, Aké-Castillo JA. 2007. Phytoplankton on the western coasts of Baja California in two different seasons in 1998. Sci. Mar. 71: 735-743.

Hulburt EM, Corwin N. 1972. A note on the phytoplankton distribution in the offshore water of the eastern and central Gulf of Mexico. Caribb. J. Sci. 12: 29-38.

Kabanova Yu, López-Baluja L. 1973. Producción primaria en la región meridional del Golfo de México y cerca de la costa noroccidental de Cuba. Academia de Ciencias de Cuba, Instituto de Oceanología, Ser. Oceanol. 16: 1-34.

Lee HY, Fryxell GA. 1996. Bicapitate Nitzschia species: Abundant nanoplankton in aggregates during November-December (1992) in the equatorial Pacific. J. Plankton Res. 18: 1271-1294.

Licea S. 1994. Thalassiosira species from the southern Gulf of Mexico. Proc. 11th Int. Diatom Symp. Mem. California Acad. Sci. 17: 311-335.

Licea S, Santoyo H. 1991. Algunas características ecológicas del fitoplancton de la región central de la Bahía de Campeche. An. Inst. Cienc. Mar Limnol. Univ. Nac. Autón. Méx. 18: 157-167.

Licea S, Luna R. 1999. Spatio-temporal variations of phytoplankton on the continental margin in the SW Gulf of Mexico. Rev. Soc. Mex. Hist. Nat. 49: 83-99.

Licea S, Zamudio ME, Luna R, Soto J. 2004. Free-living dinoflagellates in the southern Gulf of Mexico: Report of data (1979-2002). Phycol. Res. 52: 419-428.

López-Calderón J, Manzo-Monroy H, Santamaría-del-Ángel E, Castro R, González-Silvera A, Millán-Núñez R. 2006. Mesoescale variability of the Mexican Tropical Pacific using TOPEX and SeaWiFS data. Cienc. Mar. 32: 539-549.

Margalef R. 1958. Temporal succession and spatial heterogeneity in phytoplankton. In: Buzzati-Traverso AA (ed.), Perspectives in Marine Biology. Univ. California Press, Berkeley, pp. 323-349. 
Margalef R. 1974. Ecología. Omega, Barcelona, 951 pp.

Margalef R. 1978. Life-forms of phytoplankton as survival alternatives in an unstable environment. Oceanol. Acta. 1: 493-509.

Mitchell-Innes BA, Winter A. 1987. Coccolithophores: A major phytoplankton component in mature upwelled waters off Cape Peninsula, South Africa in March, 1983. Mar. Biol. 95: 25-30.

Monreal-Gómez MA, Salas-de León DA, Padilla-Pilotze AR, Alatorre-Mendieta MA. 1992. Hydrography and estimation of density currents in the southern part of the Bay of Campeche, Mexico. Cienc. Mar. 18(4): 115-133.

Moreno-Ruiz JL, Soto JP, Zamudio ME, Hernández-Becerril DU, Licea S. 1993. Morphology and taxonomy of Chaetoceros diversus Cleve (Bacillariophyceae), with reference to material from the Southern Gulf of Mexico. Diat. Res. 8: 419-428.

Moreno JL, Licea S. 1994. Morphology of three related Coscinodiscus Ehrenberg taxa from the southern Gulf of Mexico and coastal North Pacific of Mexico. Proc. 11th Int. Diatom Symp. Mem. California Acad. Sci. 17: 113-127.

Norris DR, Berner Jr LD. 1970. Thecal morphology of selected species of Dinophysis (Dinoflagellata) from the Gulf of Mexico. Contrib. Mar. Sci. 1: 146-191.

Okolodkov YB. 2003. A review of Russian plankton research in the Gulf of Mexico and the Caribbean in the 1960-1980s. Hidrobiologica 13: 207-221.

Ortiz-Zamora G, Huerta-Díaz MA, Salas-de-León DA, MonrealGómez MA. 2002. Degrees of pyritization in the Gulf of Mexico in sediments influenced by the Coatzacoalcos and GrijalvaUsumacinta rivers. Cienc. Mar. 28: 369-379.

Reynolds CS. 1995. Succesional change in the planktonic vegetation: Species, structures, scales. In: Joint I (ed.), Molecular Ecology of Aquatic Microbes. Springer-Verlag, Berlin, pp. 115-132.

Riverón-Enzástiga ML. 2008. Análisis de la variabilidad de las descargas de agua de los principales ríos de la cuenca del Golfo de México. Tesis de licenciatura, Facultad de Ciencias, Universidad Nacional Autónoma de México, 86 pp.

Salas-de León DA, Monreal-Gómez MA, Sanvicente-Añorve L, Flores-Coto C. 1998. Influence de la circulation à long terme sur la répartition des organismes zooplanctoniques dans la Baie de Campeche, Mexique. Oceanol. Acta. 21: 87-93.
Salas-de León DA, Monreal-Gómez MA, Signoret M, Aldeco J. 2004. Anticyclonic-cyclonic eddies and their impact on near-surface chlorophyll stocks and oxygen supersaturation over the Campeche Canyon, Gulf of Mexico. J. Geophys. Res. 109: 1-10.

Sánchez-Iturbe A, Flores-Coto C, Zavala-García F. 2006. Seasonal variation in growth and mortality of larval Syacium gunteri (Piscis: Paralichthyidae) in the southern Gulf of Mexico (1992 and 1993). Cienc. Mar. 32: 83-95.

Santoyo H, Signoret M. 1973. Hidrología y fitoplancton en un transecto de la plataforma continental de la Bahía de Campeche, México (agosto de 1972). Rev. Latinoam. Microbiol. 15: 207-215.

Santoyo H, Signoret M. 1975. Variación nictemeral del fitoplancton en la Bahía de Campeche, México. Rev. Latinoam. Microbiol. 17: 161-167.

Saunders RP, Glenn DA. 1969. Memoirs of the Hourglass Cruises: Diatoms. Fla. Dept. Nat. Resour. Mar. Res. Lab. 1 (Pt. III), 119 pp.

Signoret M, Bulit C, Pérez R. 1998. Patrones de distribución de clorofila $a$ y producción primaria en aguas del Golfo de México y Mar Caribe. Hidrobiológica 8: 81-88.

Smayda T. 1980. Phytoplankton species succession. In: Morris I (ed.), The Physiological Ecology of Phytoplankton. Univ. California Press, Berkeley, pp. 493-570.

Steidinger KA, Williams J. 1970. Memoirs of the Hourglass Cruises: Dinoflagellates. Fla. Dept. Nat. Resour. Mar. Res. Lab. 2 (Pt. III), $251 \mathrm{pp}$.

Toner M, Kirwan AD, Poje AC, Canta LH, Müller-Karger FE, Jones CK. 2003. Chlorophyll dispersal by eddy-eddy interactions in the Gulf of Mexico. J. Geophys. Res. 108: 3105, 12 pp.

Tyrrell T, Merico A. 2004. Emiliana huxleyi: Bloom observation and the conditions that induce them. In: Thiertein HR, Young JR (eds.), Coccolithophores: From Molecular Process to Global Impact. Springer, Berlin, pp. 75-97.

Winter A, Elbrächter M, Krause G. 1999. Subtropical coccolithophorids in the Weddell Sea. Deep-Sea Res. I 46: 439-449.

Zernova VV. 1974. Distribution of the biomass of phytoplankton in the tropical Atlantic Ocean. Okeanologiya 14: 1070-1076.

Recibido en mayo de 2007; aceptado en febrero de 2008. 